\title{
Michel Foucault e 0 nascimento da modernidade
}

\author{
JOSÉTERNES
}

RESUMO: O artigo investiga a leitura de Michel Foucault a respeito da origem do pensamento moderno na virada do século XVIII para o século XIX. Essencialmente diferente do pensamento clássico, o moderno se enraiza na história, no condicionado, na finitude. Aí, novos objetos se tornam possíveis (vida, produção, linguagem), bem como uma nova filosofia (a crítica). $E$, do interior desse espaço epistêmico novo, uma figura ausente na tradição do pensamento ocidental: o Homem.

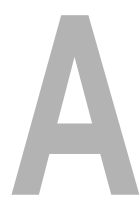

morte de Foucault, há dez anos, não tirou a sua atualidade. Sua presença entre nós, no entanto, acontece de outra maneira. É o que parecem dizer estas palavras de Jean-Jacques Courtine, de 1991: "As controvérsias de ontem se acalmaram. O tempo não é mais aquele em que era necessário ser a favor ou contra Foucault, repetí-lo ou esquecê-lo, desmontar, por toda parte, a seu exemplo, insidiosas máquinas de poder ou denunciar nessa obra o perigoso niilismo do pensamento 68 . Novos problemas surgiram que deslocam o espaço das leituras possíveis, colocam a seus textos questões inéditas, convidam-nos a lançar um olhar inquieto sobre o que têm sido nossas maneiras de ler Foucault" (Courtine, 1992, p. 112).

"Nossas maneiras de ler Foucault...". Ele mesmo nos ensina o que é uma boa leitura. Trata-se, particularmente, de interrogar nossa relação com o livro, com a obra. O Prefácio à segunda edição de História da Loucura (1972) responde: "Gostaria que um livro, (...), nada fosse além das frases de que é feito (...). Gostaria que esse objeto-acontecimento, quase imperceptível entre tantos outros, se recopiasse, se desdobrasse, desaparecesse enfim sem que aquele a quem aconteceu escrevê-lo pudesse alguma vez reivindicar o
UNITERIMOS:

discurso,

episteme, representação, modernidade, história, finitude, homem.
Este texto foi redigido, em primeira mão, para a Semana de Filosofia da UFG, em novembro de 1993. Para este Simpósio foram feitas modificações, sem alterar, substancialmente, sua estrutura.

Professor do Departamento de Filosofia da UFG e da UCG 
TERNES, José. Michel Foucault e o nascimento da modernidade. Tempo Social; Rev. Sociol. USP, S. Paulo, 7(1-2): 45-52, outubro de 1995.

1 "Está pois certo e na melhor ordem dizer-se que com filosofia nada se pode fazer. $\mathrm{O}$ errado seria pensar que, com isso, terminou o juízo sobre a filosofia. Pois sobrevém-lhe ainda um pequeno acréscimo na forma de uma contrapergunta: se nós nada poderemos fazer com filosofia, acaso a filosofia também não poderá fazer alguma coisa conosco, contanto que nos abandonemos a ela?" (Heidegger, 1969, p. 42-43).

Recomendaria, a esse respeito, a leitura do excelente texto de Paul Veyne, Foucault revoluciona a história, publicado, no Brasil, pela Editora da UNB. direito de ser seu senhor, de impor o que queria dizer, ou dizer o que o livro deveria ser. Em suma, gostaria que um livro não se atribuísse a si mesmo esse estatuto de texto ao qual a pedagogia ou a crítica saberão reduzí-lo, mas que tivesse a desenvoltura de apresentar-se como discurso: simultaneamente batalha e arma, estratégia e embate ("choc"), luta e troféu ou ferida, conjunturas e vestígios, encontro irregular e cena repetível” (Foucault, 1972, p. 10).

Temos aí, resumidamente, uma teoria do discurso. A noção foucaultiana de discurso desclassifica o autor, a obra, todo e qualquer ponto de apoio anterior à palavra viva. Desclassifica o sujeito. Somente a morte do sujeito abre espaço para o retorno da linguagem.

Esse ponto de partida nos remete a um Foucault, para muitos, ultrapassado, ou, pelo menos, desconhecido: o Foucault de A arqueologia do saber. Voltar, hoje, a As palavras e as coisas, a Nascimento da clínica, a História da loucura não seria cometer um anacronismo? Não seria, de certa forma, contradizer o próprio autor que, de público, confessara, em $O$ retorno da moral, em 1984, sua ruptura brusca entre o estilo anterior a 75 e o que se lhe segue? As palavras e as coisas, em especial, apesar de toda a polêmica desencadeada na época de seu nascimento, ainda não deu, acredito, os frutos que poderia dar. Voltar a este texto, bem como a todos aqueles discursos um tanto enigmáticos da primeira fase, se constitui, para mim, um desafio. Duplo desafio. Primeiro, porque significa vencer um certo modismo que a difusão da genealogia do poder suscitou no universo acadêmico. Depois, porque há uma dificuldade intrínseca à própria obra arqueológica. Talvez a própria rapidez de produção e divulgação dos escritos posteriores a A arqueologia do saber tenham ocasionado uma espécie de atropelo à compreensão das primeiras obras. Hoje, no entanto, como observa Courtine, "as condições de recepção do trabalho de Foucault se modificaram, com efeito, consideravelmente" (Courtine, 1992, p. 112). Não haveria muito sentido, pois, distante já de sua morte, alimentar-se da aura do Foucault vivo. Superadas as querelas próprias de seu tempo, talvez a obra de Foucault nos possa oferecer novas questões, contanto que, parodiando Heidegger, a ela nos abandonemos ${ }^{1}$.

Talvez nem se trate de levantar novas questões. Minha leitura de alguns textos de Foucault pretende muito pouco: retomar a interpretação foucaultiana da modernidade (uma palavra, hoje, muito em voga, ambígua, no entanto). Significa, no contexto de As palavras e as coisas, interrogar as condições dentro das quais se tornou possível a maneira moderna de pensar. AArqueologia, convém lembrar, distancia-se radicalmente das histórias que conhecemos na cultura ocidental ${ }^{2}$. Em primeiro lugar, precisamos lembrar que Foucault é tributário de uma herança teórica que, desde as primeiras décadas deste século, vem contestando um certo tipo de história, em especial, no que concerne à história das ciências. Ele deve muito a Bachelard, a Cavaillés, a Canguilhem. Por isso, sua história não traça linearidades. Não se contenta com as grandes causalidades. Não se ocupa com isto que tanto fascina o historiador, os fatos. Por outro lado, sua história também não se identifica com as 
TERNES, José. Michel Foucault e o nascimento da modernidade. Tempo Social; Rev. Sociol. USP, S. Paulo, 7(1-2): 45-52, outubro de 1995.

histórias das idéias, características do pensamento francês deste século. $A$ arqueologia do saber propõe-se uma tarefa muito precisa: ela descreve epistemes.

Ocupar-se com a descrição das epistemes, assinala G. Canguilhem, não faz de Foucault um epistemólogo. Seu objeto, com efeito, não é a ciência, nem qualquer outro saber em particular. Trata-se de interrogar o solo a partir do qual determinadas coisas podem ser ditas, certos discursos podem aflorar, e outros, não. Trata-se, enfim, de se situar nessa região mais fundamental, nesse humus, lembrando novamente Canguilhem, que alimenta o modo de pensar de uma cultura numa determinada época. De acordo com o Prefácio de As palavras e as coisas, todo discurso obedece a uma ordem. "O embaraço que faz rir quando se lê Borges é por certo aparentado ao profundo mal-estar daqueles cuja linguagem está arruinada: ter perdido o comum do lugar e do nome" (Foucault, 1966, p.10). A Enciclopédia Chinesa, a que alude Borges, se enraíza em outro espaço a partir do qual se torna possível "nomear, falar, pensar" (p. 11) e que, para nós, modernos, se reverte, simplesmente, no impensável, "a impossibilidade patente de pensar isso" (p. 7).

Os estudos chamados arqueológicos de Foucault privilegiam dois recortes na cultura européia ocidental: a episteme clássica (séculos XVII-XVIII) e a episteme moderna (séculos XIX-XX), à qual ainda pertencemos ${ }^{3}$. Dois recortes que separam, insisto, duas maneiras de pensar. Diferenças, portanto, epistêmicas. Trata-se de verificar que tipo de questões, de conceitos, de saberes perdem sentido, e que maneiras de pensar tomam seu lugar. Foucault reconhece que pisa um terreno movediço: "Não é fácil estabelecer o estatuto das continuidades para a história em geral. Menos ainda, sem dúvida, para a história do pensamento. Pretende-se traçar uma divisória? Todo limite não é mais talvez que um corte arbitrário num conjunto indefinidamente móvel. Pretende-se demarcar um período? Tem-se porém o direito de estabelecer, em dois pontos do tempo, rupturas simétricas, para fazer aparecer entre elas um sistema contínuo e unitário? A partir de que, então, ele se constituiria e a partir de que, em seguida, se desvaneceria e se deslocaria? A que regime poderiam obedecer ao mesmo tempo sua existência e seu desaparecimento? Se ele tem em si seu princípio de coerência, donde viria o elemento estranho capaz de recusá-lo? Como pode um pensamento esquivar-se de outra coisa que ele próprio? Que quer dizer, de um modo geral: não mais poder pensar um pensamento? E inaugurar um pensamento novo?" (Foucault, 1966, p. 64). A Arqueologia, certamente, não conta com os instrumentos necessários para responder a todas estas perguntas. Elas constituem, porém, a meu ver, o motivo que alimenta a própria investigação que se desdobra na ordem empírica. E é aí, na ordem empírica, que se constatam descontinuidades. Por exemplo: não se pode ir da idade clássica à modernidade em linha reta. Esta, a modernidade, não se constitui no aperfeiçoamento daquela. A diferença, diria A. Koyré, não é de grau, mas de natureza. Aí, certamente, se pode perceber um dos traços fundamentais das histórias construídas por Foucault.

${ }^{3}$ Rigorosamente, para Foucault, a expressão pós-modernidade não tem sentido. 
TERNES, José. Michel Foucault e o nascimento da modernidade. Tempo Social; Rev. Sociol. USP, S. Paulo, 7(1-2): 45-52, outubro de 1995.

${ }^{4}$ Para Foucault, simplesmente, idade da representação. Mas o infinito, a meu ver, ainda que não tematizado explicitamente, parece constantemente aflorar co-mo questão constitutiva dessa idade. Indecisão, a meu ver, estreitamente ligada à escolha teórica da leitura de Foucault: as Regulae ad Directionem Ingenii, de Descartes.

${ }^{5}$ A noção cartesiana de idéia "como imagem do mundo" pode ser encontrada na Terceira Meditação.

${ }^{6}$ Heidegger, num texto da coletânea Holzwege, fala em "Época da imagem do mundo". Fica a pergunta se a redução do modo de pensar do século XVII e XVIII à forma generalizada da representação é absoluta. Temos exemplos, mesmo de dentro dessa época, que parecem transgredir a ordem descrita por Foucault. Refiro-me, em particular, a Espinosa e a Pascal.
As palavras e as coisas, em particular, nos oferece, em linhas bastante amplas, o quadro geral da idade clássica. Trata-se do universo da ordem e da representação, o universo infinito ${ }^{4}$. Uma época em que as palavras e as coisas se distanciam. Em que estas, as coisas, não mais falam, não mais guardam uma verdade secular. $\mathrm{O}$ mundo deixa de ser texto indefinidamente interpretável. A verdade se dá na transparência do Discurso. Vale a pena assinalar bem este acontecimento, a passagem do Texto para o Discurso. Um texto está à nossa disposição para ser lido. Deve ser interpretado. Já o discurso se basta a si mesmo. É transparente. Funciona por uma espécie de mecanismo próprio. Desdobra-se ao infinito. Não se trata de interpretá-lo, pois se caracteriza pela simplicidade e evidência. Resta-nos acompanhar o seu desenrolar. Assim, à hermenêutica renascentista se contrapõe, com os clássicos, a necessidade de uma analítica. Os renascentistas interpretam. Os clássicos analisam. E isto tem um sentido duplo: analisa-se a linguagem, em primeiro lugar, a distribuição linear, sucessiva, dos signos. E, por outro lado, analisa-se, também, o pensamento. A noção clássica de signo incorpora a idéia e a própria noção de idéia (ou a idéia da idéia). Linguagem e pensamento, de alguma forma, se sobrepõem. Foucault afirma, mesmo, que a linguagem se destrói, desaparece. O Cogito, radicalizado, dispensaria a linguagem. Contentar-se-ia com a idéia "como imagem do mundo" ${ }^{5}$. Esse contentar-se com idéias, com a realidade reduzida a traços geométricos, onde, segundo A. Koyré, "não experimentamos nenhuma alegria perante a variedade das coisas" (Koyré, 1973, p. 58), essa maneira de conhecer fundada na medida e na ordem recebe o nome de idade da representação ${ }^{6}$. Uma época que, para Foucault, é bastante longa. Estende-se do início do século XVII até a aurora do século XIX.

A partir do final do século XVIII e começo do século passado a episteme ocidental se reorganiza. Configura-se uma disposição do saber radicalmente nova. Já não nos contentamos com analisar representações. A verdade não mais habita o universo transparente das idéias. Precisamos arrancála à espessura das coisas. Dá-se no interior da história.

Os esforços de alguns filósofos, como Husserl, para encontrar um novo caminho seguro para a Razão fracassam inexoravelmente. Na verdade, eles não perceberam que não é mais possível voltar a Descartes. Todo o solo que sustenta nossa maneira de pensar é outro. A nova disposição epistêmica incorpora a historicidade, o condicionado, a finitude. Ou seja, desde o fim do século XVIII, perdemos a ilusão do fundamento absoluto do conhecimento. Foucault vai além: mostra a ausência de todo fundamento. Quando os modernos fundam o saber no finito, despertam de um longo sono dogmático. Ao se situarem na historicidade de seus objetos, engajam-se numa tarefa marcada pelo tempo, pela dispersão, pela destruição, pela morte.

É nesse terreno, o da historicidade e da finitude, que vemos nascer novos discursos. É nesse contexto epistemológico que emergem figuras antes impossíveis de imaginar: a produção, a vida, a linguagem são novos objetos próprios da modernidade. Os clássicos não tinham nada disso. Não faziam 
TERNES, José. Michel Foucault e o nascimento da modernidade. Tempo Social; Rev. Sociol. USP, S. Paulo, 7(1-2): 45-52, outubro de 1995.

economia política, mas analisavam riquezas. Não faziam biologia, mas história natural. Não faziam filologia, ou gramática comparada, mas se ocupavam com algo muito estranho para nós, hoje, gramática filosófica (ou geral). Contemporânea a essas empiricidades, o final do século XVIII viu nascer uma outra maneira de se fazer filosofia. Já não se trata mais unicamente de se ocupar com o desenrolar das representações. A nova filosofia ousa interrogar a possibilidade mesma da representação. A figura mais ilustre dessa episteme é Kant, uma filosofia transcendental.

A análise de Foucault não pára aí. A modernidade não se exaure nessa dualidade inicial. Ciências empíricas e filosofia transcendental constituem um espaço epistemológico tal que, de seu próprio interior, se impõe uma terceira figura: o homem. Seu advento, no limiar de nossa época, não é fruto do acaso. Ele é requerido pela própria contextura do saber moderno. Isto não quer dizer que hoje sejamos mais humanos do que nos séculos anteriores. Não está em questão o ressurgimento do humanismo. Aquestão é outra: os modernos não conseguem mais pensar sem uma referência, ainda que velada, ao homem. Trata-se, pois, de uma época inapelavelmente antropológica. Isto, para Foucault, não é, de forma nenhuma, um elogio. Ao contrário, se, de um lado, o homem se constitui numa figura central da disposição epistemológica atual, por outro, significa uma nova perversão. O espectro do dogmatismo, objeto privilegiado da crítica kantiana, talvez não esteja totalmente afastado de nosso pensamento. Ao contrário, encontra, no entender de Foucault, seu lugar de entrada justamente no espaço aberto pela quarta, e mais fundamental, questão posta por Kant em sua Lógica: o que é o homem? ${ }^{7}$

Desde História da loucura vemos Foucault afirmar que a filosofia moderna é, em essência, antropologia (Foucault, 1972, p. 169). Em As palavras e as coisas, torna-se tese fundamental: "A antropologia como analítica do homem teve indubitavelmente um papel constituinte no pensamento moderno, pois que em grande parte ainda não nos desprendemos dela" (Foucault, 1966, p. 351). Kant, aqui, tem, na verdade, um lugar simbólico. O que ele estabeleceu, ou indicou, foi apenas o vazio que tornaria a questão "o que é o homem?" possível. E este espaço se localiza na distinção kantiana entre o empírico e o transcendental. Distinção, observa Foucault, que Kant "mostrara" (Foucault, 1966, p. 352) e que a filosofia pós-kantiana teria negligenciado.

Deve-se insistir nessa negligência. Ela traduz a ambigüidade do estatuto do homem no pensamento filosófico moderno. Acreditam as boas almas ${ }^{8}$ que, finalmente, se anuncia uma nova idade do homem. Trata-se, certamente, de um delírio humanista. Ora transformam o empírico em fundamento. Ora fazem do transcendental objeto da experiência ${ }^{9}$. Em ambos os casos, absolutizam um pensamento que, desde seu nascimento, se configura relativo, disperso, finito. Negam o próprio ser da modernidade. Instauram, assim, através da antropologia, um novo dogmatismo. Então, diz Foucault, "todo conhecimento empírico, desde que concernente ao homem, vale como campo filosófico possível, onde se deve descobrir o fundamento do conheci-

${ }^{7}$ A Lógica, ao expor o campo (Feld) próprio da filosofia, amplia esse interesse para quatro perguntas (Fragen) essenciais. Às três anteriores vemos acrescida uma quarta, Was ist der Mensch?, que, segundo Foucault, seria mais fundamental, já que aquelas estariam reportadas a ela e "postas, de certo modo, à sua custa (Foucault, 1966, p. 352). Aliás, é justamente isto que dizem as palavras de Kant: "Die erste Frage beantwortet die Metaphysik, die zweite die Moral, die dritte die Religion, und die vierte die Anthropologie. Im Grunde kônnte man aber alles dieses zur Anthropologie rechnen, weil sich die drei ernsten Fragen auf die letzte beziehen" (KANT, 1983, p. 448).

8 "les belles âmes" (Foucault, 1966, p. 352).

9 “... en fait, il s'agit, et c'est plus prosaique et c'est moins moral, d'un redoublement empirico-critique par lequel on essaie de faire valoir l'homme de la nature, de l'échange, ou du discours comme le fondement de sa propre finitude. En ce Pli, la fonction transcendentale vient recouvrir de son réseau impérieux l'espace inerte et gris de l'empiricité; inversement, les contenus empiriques s'animent, se redressent peu à peu, se mettent debout et sont subsumés aussitôt dans un discours qui porte au loin leur présomption transcendentale" (Foucault, 1966, p. 352). 
mento, a definição de seus limites e, finalmente, a verdade de toda verdade. A configuração antropológica da filosofia moderna consiste em desdobrar o dogmatismo, reparti-lo em dois níveis diferentes que se apóiam um no outro e se limitam um pelo outro: a análise pré-crítica do que é o homem em sua essência converte-se na analítica de tudo o que pode dar-se em geral à experiência do homem" (Foucault, 1966, p. 352).

Não se trata, parece-me, de, simplesmente, eliminar a antropologia do horizonte da modernidade. Mesmo porque, diz Foucault, "constitui talvez a disposição fundamental que comandou e conduziu o pensamento filosófico desde Kant até nós" (Foucault, 1966, p. 353). Trata-se de devolver-lhe o seu peso devido. Trata-se de conferir ao homem o lugar que lhe convém. De que Kant, aliás, já suspeitara: indicação, apenas. Não fundamento. Pois não há mais, na episteme moderna, nenhum fundamento. Todo fundamento dispensa o pensar. Impõe a sonolência intelectual. Foucault descobre em Nietzsche a direção (ou alternativa) desejável para o pensamento moderno. É preciso, com efeito, desenraizar a antropologia. Como já se observara no Sofista, a possibilidade do pensar tem a ver com a morte. Desta vez, no entanto, trata-se de um duplo assassinato: “... Nietzsche reencontrou o ponto onde o homem e Deus pertencem um ao outro, onde a morte do segundo é sinônimo do desaparecimento do primeiro, e onde a promessa do super-homem significa, primeiramente e antes de tudo, a iminência da morte do homem" (Foucault, 1966, p. 353). Morte de Deus, morte do homem... Foucault insiste no significado desse acontecimento. Não se trata, aí, de uma carência aberta na cultura ocidental. Não se trata, também, de uma lacuna. A morte do homem tem o sentido do vazio, da casa vazia, de que nos fala Deleuze (Deleuze, 1982, p. $291 \mathrm{ss).}$ Na idade clássica, e é isto que o quadro de Velázquez, analisado por Foucault no começo de As palavras e as coisas, ensina, a ausência do homem se dera face ao infinito discursivo. Na modernidade, no entanto, vimos, sua presença é requerida. Mas, entenda-se, enquanto sujeito e objeto do conhecimento. Desde o começo, portanto, enquanto figura ambivalente, necessariamente nebulosa. Constitui, portanto, negação da própria filosofia moderna "conduzir todo o conhecimento às verdades do homem” (Foucault, 1966, p. 353). Quando isto ocorre, instaura-se um novo antropologismo. É esse tipo de filosofia, "essas formas de reflexão canhestras e distorcidas", que merecem "um riso filosófico" ${ }^{10}$. Foucault, à maneira de Kant, quer um novo fim da metafísica: "Em nossos dias não se pode mais pensar senão no vazio do homem desaparecido" (p. 353).

Para concluir, gostaria de ressaltar o seguinte: os dois grandes recortes a que Foucault procede em suas análises podem deixar a impressão de uma espécie de tirania das epistemes. Num colóquio a respeito de As palavras e as coisas, realizado em 1968, E. Verley afirma: "É surpreendente ver até que ponto as articulações assinaladas por Cassirer desaparecem no quadro

${ }^{10}$ Un rire philosophique (Foucault, 1966, p. 354). do pensamento clássico que encontramos em As palavras e as coisas" (Verley, 1970, p. 160). Penso que essa suspeita não pode ser absolutizada. O próprio 
TERNES, José. Michel Foucault e o nascimento da modernidade. Tempo Social; Rev. Sociol. USP, S. Paulo, 7(1-2): 45-52, outubro de 1995.

discurso foucaultiano, como bem observa Renato Janine Ribeiro, em um livro recente, é um discurso do inesperado (Ribeiro, 1993, p. 74). Encontramos, desde História da loucura, figuras-surpresas que, de alguma forma, transgridem a ordem imposta pela episteme. Trata-se de pensamentos que, poderse-ia dizer, não pertencem a nenhuma episteme, mas se inscrevem em suas margens. São, conforme tenho mostrado em minha tese de doutoramento, pensamentos-limite. $\mathrm{O}$ interesse foucaultiano pelo limite, pelas fronteiras, pelas dobras, pelo indefinido, o quase-outro, não me parece ocasional. Talvez seja um de seus traços mais marcantes. Judith Revel, num texto recente, diz: “... da Introdução de 1954 aos últimos volumes da História da sexualidade, em 1984, alguma coisa, precisamente, permanece, para além das rupturas, para além das mudanças metodológicas - alguma coisa que eu acredito ser um certo pensamento da experiência como experiência-limite, ou como experiência do limite" (Revel, 1992, p. 52). O limite aponta a diferença, o perigo, o "descaminho daquele que conhece" (Foucault, 1984, p.13).

Recebido para publicação em abril/1995

TERNES, José. Michel Foucault and the birth of modernity. Tempo Social; Rev. Sociol. USP, S. Paulo, 7(1-2): 45-52, october 1995.

ABSTRACT: The article investigates the reading of Michel Foucault with respect to the origin of modern thinking in the turning of the eighteenth to the nineteenth century. Essencially different from classic thinking, the modern thinking roots itself in history, in the conditioned, in finitude. There, new objects turn themselves possible (life, production, language), as well as a new philosophy (a critical one). And, from inside this new epistemic space, a figure which was absent in the tradition of western thought: Man.

UNITERMS:

discourse, episteme, representation, modernity, history, finitude, man.

\section{REFERÊNCIASBIBUOGRÁFICAS}

Courtine, J. J.(1992) Entre la vie et la mort. Apud GiARD, L. (org.). Michel Foucault: Lire l'oeuvre. Grenoble, Jérôme Millon.

DeleuZe, Gilles. (1982) Em que se pode reconhecer o estruturalismo. In: Châtelet, F. História da Filosofia. VIII. O Século XX. Trad. de H. Japiassú. Rio de Janeiro, Zahar.

Foucault, Michel. (1966) Les mots et les choses. Paris, Gallimard. . (1972) Histoire de la folie à l'âge classique. Paris, Gallimard. 
- (1984) História da sexualidade II - O uso dos prazeres. Rio de Janeiro, Graal.

Heidegger, Martin.(1969) Introdução à Metafísica. Trad. de E. C. Leão. Rio de Janeiro, Tempo Brasileiro.

KANT, I. (1983) Logik. A, 26. Darmstadt, Wissenschaftliche Buchgesellschaft.

KoYRÉ, A. (1973) Études d'histoire de la pensée scientifique. Paris, Gallimard.

REVEL, Judith. (1954) Sur l'introduction à Binswanger (1954). In: GIARD, L. (org.). Michel Foucault: Lire l'oeuvre. Grenoble, Jérôme Millon.

Ribeiro, Renato Janine. (1993) A última razão dos reis. São Paulo, Companhia das Letras.

Verley, E. (1970) Coloquio sobre las palabras y las cosas. In: Analisis de Michel Foucault. Buenos Aires, Tempo Contemporaneo. 